\title{
VOCES MÍTICAS GESTADAS EN LA SOMBRA DE LAS MINAS DEL CARBÓN: UN ENFOQUE SEMIÓTICO ${ }^{\mathbf{1}}$ \\ Mythical voices generated at the coal mine's shade: semiotics approach
}

\section{Juan Bahamonde Cantín*}

Resumen

Análisis de un corpus de textos míticos relatados por exmineros de la zona del carbón de la Región del Biobío (Chile). En primer lugar se observa en los textos seleccionados (casos y leyendas) la memoria sensorial como proceso de actualización psicológica cognitiva y semiótica. En segundo lugar se analizan los discursos míticos desde dos perspectivas: la teoría semiótica de los signos naturales de Umberto Eco y la semiosis de Charles Morris. Finalmente, el trabajo aporta diferencias estructurales entre estas dos superestructuras discursivas orales utilizadas por los informantes: el caso y la leyenda.

Palabras clave: Textos míticos, memoria sensorial, signos naturales, semiosis, caso, leyenda.

\section{Abstract}

This article is related to the field of oral literature. It is focused on a theoretical and analytical approach in the corpus of mythical texts narrated by former miners from the Coal District of the Bío-Bío Region (Chile). Firstly, sensory memory is found in the texts as a process of updating (cognitive and semiotic psychology). Secondly, the mythical discourses are analyzed from two perspectives: the semiotics theory of natural signs of Umberto Eco and the semiosis of Charles Morris. Finally, this work shows structural differences between these two superstructures used by the informant miners: the case and the legend.

Key words: Mythical texts, sensory memory, natural signs, semiosis, case, legend.

\section{ANTECEDENTES}

A pesar del cierre de los yacimientos carboníferos de la Región del Biobío (1997), ${ }^{2}$ la rica experiencia de los mineros y de sus familias se ha ido manteniendo en

\footnotetext{
${ }^{1}$ Los textos míticos analizados en este trabajo forman parte del corpus recopilado en el proyecto de investigación DIUBB 084726 1/R, titulado: "Creencias populares, casos y leyendas gestadas en torno a las minas del carbón...” (2008-2010), que se desarrolló en la Universidad del Bío-Bío, Concepción, a cargo del autor de este artículo y de la profesora Margarita Gatica Villarroel, como coinvestigadora.

${ }^{2}$ Por ciento cincuenta años funcionó la industria del carbón (ver Pueblo Nuevo. Historia, mitos y leyendas de la Zona del Carbón, de Miguel Elizalde, inédito, 2006:5). Además, según las informaciones de los propios ex mineros, las minas de Schwager (Coronel) se cerraron en 1994. Por su parte, las minas de Lota dejaron de funcionar en 1997. En los yacimientos de ENACAR situados en Curanilahue (pequeña ciudad industrial que se levanta en los faldeos de la cordillera de Nahuelbuta), la situación fue diferente: "Colico Sur" cerró en 1992; "Trongol Norte", en el 2006 y la Compañía Carbonífera Victoria de Lebu (CARVILE), en el 2008. Actualmente en Curanilahue funcionan pirquenes y un buen número de personas vive en torno a la minería de superficie. En consecuencia, en la zona de la Región del Biobío todavía se desarrolla, aunque en menor proporción que antes, la explotación del carbón.
} 


\section{Juan Bahamonde Cantin}

la memoria y en la tradición oral generada al respecto. Por lo mismo, nos concentraremos en el análisis de una selección de relatos míticos (siete casos y una leyenda representativa) recopilados in situ mediante encuesta semiformal aplicada a exmineros en las ciudades de Coronel, Lota $^{3}$ y Curanilahue. ${ }^{4}$

En concordancia con lo manifestado anteriormente, el minero entregó su vida laborando la "veta" de carbón. ${ }^{6}$ Las funciones desarrolladas en la mina eran numerosas y variadas, pues, todo trabajador se iniciaba como "apir" (peón, ayudante del contratista), a muy temprana edad; continuaba su trabajo en las estrechas galerías, asumiendo diversos roles laborales ("palero", "barretero", "disparador", etc.); más tarde alcanzaba una responsabilidad mayor al desempeñarse como "contratista" (minero con más experiencia, a cargo de dos o más operarios) ${ }^{7} \mathrm{y}$, finalmente, en su edad madura, aspiraba al cargo de "mayordomo".

En los yacimientos carboníferos de la Región del Biobío, el ingreso a la galería principal de la mina (o vía principal) se hacía por un chiflón ${ }^{8}$ o pique. ${ }^{9} \mathrm{Al}$ chiflón se ingresaba por una pendiente o plano inclinado; en cambio para bajar al pique había que introducirse en un ascensor o jaula que descendía a más de 500 metros bajo el nivel del mar, y luego caminar por las galerías hasta llegar al denominado "frente" de explotación. ${ }^{10}$ En este espacio la vida del trabajador siempre estaba en peligro y desde los inicios de la minería (mediados del siglo XIX) hasta el cierre de la explotación (1997) se va creando y recreando una forma de vida particular con características específicas. Esta cultura tiene su génesis en una condición campesina primaria, por cuanto el minero llega del campo a la ciudad. Este hecho, unido al influjo extranjerizante de la cultura europea manifestada en la relación con la jefatura de las minas y su propia condición de trabajo como la forma de vida colectiva, van

\footnotetext{
${ }^{3}$ Las extensas y lóbregas galerías carboníferas que permanecen sin funcionamiento, en Lota, se encuentran situadas bajo las profundidades del golfo de Arauco.

${ }^{4}$ Los mantos de carbón subterráneos de la zona de Curanilahue se sitúan bajo los faldeos de la cordillera de Nahuelbuta.

${ }^{5}$ Veta (Uribe, 1998:93): "Manto de carbón, la parte útil del material".

${ }^{6}$ La visión sincrónica de este valioso material lingüístico (relatos míticos), obtenidos mediante la aplicación del método geográfico-lingüístico, se enriquece con datos diacrónicos de este representativo espacio cultural de nuestro país, que presenta características muy propias.

${ }^{7}$ En lo concerniente a las distintas funciones desarrolladas por este jornalero en la mina, seguimos de cerca el estudio "El léxico de las minas del carbón" de Parada y Valdivieso (1974), donde se examina el lenguaje que corresponde al "ciclo laboral minero". Ver también en Uribe (1998: 94-96) una clasificación completa de los oficios de los mineros.

${ }^{8}$ Chiflón: (Uribe, 1998:91). "Galería horizontal con pendiente de acceso principal a la mina". Un buen ejemplo se encuentra en el acceso a los restos de la mina Puchoco (Coronel).

${ }^{9}$ Pique (Uribe, 1998:93): "Galería vertical de acceso principal a la mina".

${ }^{10}$ Frente (Uribe, 1998:91): "Sector donde trabajaba el minero explotando la veta". La galería principal marcaba el comienzo del mundo subterráneo, pero los mineros caminaban varios kilómetros por túneles y galerías, que conocían como la palma de su mano, hasta llegar a los frentes de explotación, donde se encontraba el "manto" o la "veta".
} 
conformando una cultura específica orientada a sus necesidades cotidianas (Uribe, 2007:207).

\section{PENSAMIENTO MÍTICO}

Retomado lo aseverado anteriormente, este estudio está vinculado a la denominada "oralidad primaria". ${ }^{11}$ En este sentido, desde una postura émica (K. L. Pike, 1954), ${ }^{12}$ los narradores-protagonistas (exmineros) pueden recordar y reactualizar en cada relato un cierto "evento primordial" (Carrasco, 1989:42), que se traduce en dos tipos de superestructura (Van Dijk, 1980) narrativa: caso (relatos centrados en experiencias personales) y leyenda (narraciones perpetuadas en la comunidad minera). ${ }^{13}$ Es decir, este interesante legado oral se ha perpetuado gracias al pensamiento mítico, ${ }^{14}$ que conserva, en la memoria de los habitantes de Lota, Coronel y Curanilahue, un patrimonio narrativo de un valor inmenso, estructurado en variados relatos mediante los cuales el minero fabula con los elementos propios de un espacio tenebroso (sub terra, en palabras de Baldomero Lillo), en un intento por explicar su propia subsistencia en el trabajo y el mundo misterioso que lo rodeaba. Siguiendo a Malinowski (1963:32), podemos manifestar que — a pesar de que hace varias décadas estas minas carboníferas se cerraron- se preserva en la memoria a largo plazo (MLP) de estos exmineros una "realidad viviente" que trae voces del pasado a su entorno actual, constituyendo una valiosa herencia cultural. De estos relatos se analizan aquí algunos casos, el tipo de discurso más abundante y representativo en el corpus recopilado.

\section{RELATOS MÍTICOS ACTUALIZADOS MEDIANTE LA MEMORIA SENSORIAL}

Cabe señalar que todos los mineros entrevistados experimentaron en su actividad desarrollada en el interior de la mina diversas situaciones especiales

\footnotetext{
${ }^{11}$ Ong (1999:120) dice: ... "llamo 'oralidad primaria' a la oralidad de una cultura que carece de todo conocimiento de la escritura o de la impresión. Es 'primaria' por el contraste con la 'oralidad secundaria' de la actual cultura de alta tecnología, en la cual se mantiene una nueva oralidad mediante el teléfono, la radio... y otros aparatos electrónicos que para su existencia y funcionamiento dependen de la escritura y la impresión. Hoy la cultura oral primaria casi no existe en sentido estricto, ya que toda cultura conoce la escritura y tiene alguna experiencia de sus efectos. No obstante, en grados variables muchas culturas y subculturas, aun en un ambiente altamente tecnológico, conservan gran parte del molde mental de la oralidad primaria".

${ }^{12}$ Para Pike (1954), "cierta costumbre tradicional estaría basada en cómo explican los miembros de esa sociedad tradicional el significado y los motivos de esa costumbre".

${ }^{13}$ Los términos "caso" y "leyenda" están empleados según las teorías y usos de la investigación folclórica, asumidos por la literatura oral en la etapa de recolección y clasificación de materiales.

${ }^{14}$ Carrasco (1989:24-25) manifiesta: "Es fundamental tener en cuenta que el pensar mítico es una clase compleja (saber, sentir, creer, razonar) de pensamiento estructurado colectivo, existente en una cultura arcaica o semiarcaica y vigente o subyacente, por tanto, en la mayoría de la totalidad de miembros de esa cultura". Además agrega el estudioso: "Uno de los componentes básicos de la memoria cultural, que se define por su capacidad de recordar, más precisamente de reactualizar (en los márgenes de la conciencia de la cultura) un cierto evento primordial".
} 


\section{Juan Bahamonde Cantin}

atribuidas a la presencia del Diablo, ${ }^{15}$ experiencias que son narradas como "casos míticos testimoniales". Hemos comprobado en el trabajo en terreno que esta sensibilidad mítica se presenta con más fuerza en los exmineros más antiguos (de 80 o más años). En cambio, los mineros que estaban activos en el período de cierre de las minas, cuya edad fluctúa entre los 55 y 65 años - al parecer, por el influjo de los medios de comunicación y la postmodernidad - presentan una aparente postura escéptica hacia este ente mítico. La sensación es que les da vergüenza hablar de este tipo de creencia y responsabilizan de ella a los más antiguos, diciendo: "Mi papá también fue minero y hablaba de esas cosas". Otros manifiestan: "Tendrá que existir el fulano". Por otra parte, apoyados en la mentalidad predominantemente machista, los exmineros encuestados resaltan en sus narraciones ciertas acciones rituales que se traducen en comportamientos despectivos hacia este personaje mítico. $^{16}$

De lo expuesto hasta ahora, nuestro análisis comprobará, mediante extractos seleccionados de los textos míticos (incluyendo los de contenido "animista"), ${ }^{17}$ que los mecanismos de actualización de la macroestructura semántica, el "tema o asunto del discurso" (Van Dijk, 1989:433), dependerá de los distintos tipos de memoria sensorial que distingue la psicología cognitiva: la memoria icónica y la memoria ecoica (A. Puente, 349-350). El primer tipo de rememoración tiene relación con las representaciones visuales y espaciales $\mathrm{y}$, el segundo, con los sonidos y palabras, ${ }^{18}$ como ilustran dos casos míticos actualizados por medio de estos dos tipos de memoria que se presentan a continuación. Al mismo tiempo, en el análisis de estos textos se determinará en forma sintética la descripción de la representación sensorial y el sentido que adquiere esta representación mnemotécnica, de acuerdo con lo expresado por los informantes. ${ }^{19}$

\footnotetext{
${ }^{15}$ Según los informantes, el Diablo tiene entre los mineros otras denominaciones: "Patas de hilo", "don Sata", "Lucifer", "el Malulo", "el Caballero", etcétera.

${ }^{16}$ Estas formas de proceder se traducen en la mayoría de las veces en insultos o "bad words"; pero al mismo tiempo es importante considerar que no le sienta bien a un hombre aparecer como cobarde.

${ }^{17}$ En la subcultura minera, el narrador incluye en el relato mítico al "animista". En cambio, en la cultura mítica de Chiloé el informante distingue perfectamente entre el relato alusivo a un referente mítico (el Trauco, los Brujos, el Caleuche, por nombrar los más representativos, considerando su vigencia) y el relato "animista", relacionado con las ánimas que penan.

18 De Vega (1994:69) sostiene que una de las primeras cuestiones planteadas fue la relativa duración de la huella icónica o del icón: "memoria precategorial, un registro literal de la información visual previo a su interpretación semántica" (...). "Se ha demostrado mediante experimentos de informe parcial que los sujetos pueden informar correctamente sobre fracciones del estímulo taquistoscópico, a partir de criterios de color (vg: recordar las letras azules), localización, tamaño, brillo, movimiento y forma. Es decir, todos estos atributos visuales son propios de la huella icónica En cuanto a la memoria ecoica, De Vega (1994:79) la caracteriza como "un registro auditivo, precategorial, de gran capacidad y persistencia limitada que retiene literalmente la información del input antes de ser procesada".

${ }^{19}$ Según Cassirer (1971:119), esta forma de percepción, "lo que se ve o se siente, se halla rodeado de una atmósfera especial".
} 


\subsection{DISCURSOS MÍTICOS: LA MEMORIA SENSORIAL ECOICA}

Dentro de la mina, la presencia del Diablo es asociada con acciones que se relacionan con distintos sonidos como: "puertas de la "revuelta" ${ }^{20}$ que se abrían solas", "pasos que se sentían donde no laboraba nadie", "güinche para tirar madera que funcionaba sin haber ningún trabajador cerca", etc. ${ }^{21}$ Según Eco (1995:35), cuando en un texto mítico la asociación [entre inferencia y significación] está reconocida culturalmente y codificada sistemáticamente" se habla de "Convención semiótica". 22

Un relato que se actualiza mediante la memoria ecoica es el caso mítico que se presenta a continuación, narrado por don Juan Medina, exminero de Curanilahue, de 79 años (recopilación efectuada en Curanilahue, en la casa habitación del informante, el 16 de enero de 2009, por el autor de este artículo): ${ }^{23}$

"I: Íbamoh saliendo... se iba a tapiar eso. Y siento un chiflido finito y largo el chiflido. Y el jefe escuchó:

-A ver Juan. Oye Medina, oye Medina, ipara, para, para!

Pasó por el lado mío pa(ra) ajuera. No me dijo nada qué es lo que había sentido ni nada, si no que:

${ }_{-i P a r a}$ Medina, para Medina!

Y pasa por la orilla pa(ra) ajuera

E: ¿Y qué cree usted que fue?

I: Bueno, nos dicen que Satanás, cuando están quedando de para las minah, empieza a trajinar él".

Según la macroestructura del relato, el "jefe técnico" y el "apir" (don Juan Medina, minero-informante), haciendo uso de la memoria ecoica y procedimental, ${ }^{24}$ deciden detener las actividades por cuanto sienten la presencia del Diablo por el "silbido, largo y finito", en un sector abandonado de la mina. En este inframundo, la creencia se asimila colectivamente y no respeta las jerarquías ni las funciones de los mineros. Además, el minero finaliza el relato mítico con un mensaje de connotación laboral (a manera de complementación), reconocido culturalmente en las faenas y, por lo tanto, de carácter simbólico:

\footnotetext{
${ }^{20}$ Revueltas (Uribe, 1998:93): "Galerías de retorno del aire de ventilación”.

21 "Cuando iba a pasar algo, primero pasaba "el Caballero", o trabajaba en los cortes haciéndolos sonar, y al poco tiempo se cerraba ese frente" (ver entrevista a don Miguel Álvarez, p. 402, en el libro Coronel de ayer y de hoy de Mario Gutiérrez et al., 2000).

${ }^{22}$ Eco (1995:35) ilustra esta teoría con ejemplos prácticos: "Podemos inferir la presencia del fuego por el humo, la caída de la lluvia por el charco, el paso de un animal por la huella sobre la arena".

${ }^{23}$ En la transcripción de textos se representa con $\mathrm{E}$ al entrevistador y con I al informante entrevistado.

${ }^{24}$ Existe además otra clase de memoria denominada procedimental, que almacena los conocimientos y las acciones relacionadas con el "cómo hacer algo" (ejemplo típico del mundo supersticioso: ¿Cómo reaccionar cuando en el camino se encuentra una escalera instalada?). Una de las diferencias entre el conocimiento declarativo y procedimental es el nivel de conciencia. El conocimiento declarativo, además de expresarse con palabras, permite su acceso de manera consciente. El conocimiento procedimental, una vez consolidado, es automático. Ver este planteamiento en Tesis de Bahamonde (2008:71).
} 


\section{Juan Bahamonde Cantin}

"Cuando el proceso de explotación en alguna de las minas se iba a detener, 'Satanás' daba el aviso"; en este caso, mediante un "silbido largo", proveniente desde un mundo desconocido e inexplorado, como es el interior de la mina. ${ }^{25}$

También existen leyendas que se actualizan por medio de la memoria ecoica, como es el caso de La tacos altos, en plena vigencia entre las familias de exmineros que residen en los antiguos departamentos de los edificios de la población Schwager, sector Puchoco (Coronel). Don Mario Gutiérrez, una autoridad en la materia, sostiene: "Dicen los schwagerinos que todavía se ve la figura de la mujer, y se escucha el caminar de la mujer en los pasillos... de vez en cuando se ve la figura atravesar los muros del departamento donde ella vivía" (ver relato completo en Anexo).

\subsection{DISCURSOS MÍTICOS: LA MEMORIA SENSORIAL ICÓNICA}

Considerando el análisis de los relatos recopilados, podemos manifestar que mediante la memoria icónica se actualizan estos casos míticos, acontecidos dentro y fuera de la mina, relacionados con imágenes generalizadas del Diablo.

Los mineros que han percibido algún contacto con "el Maldito" lo describen en sus relatos de la siguiente manera: "con pantalón negro, de brillante tela", "zapatos de charol y nuevos", "dientes de oro". Otros, como don Miguel Álvarez, lo reseñan "con botas negras con inmensas espuelas y la lámpara colgando". Y otros, inclusive, lo han visto "vestido como sacerdote". Es decir, respecto de la representación del Diablo, podemos determinar que hay en las descripciones un evidente predominio de imágenes visuales tipificadoras, que se repiten en los relatos recopilados en Lota, Coronel y Curanilahue. ${ }^{26} \mathrm{Al}$ parecer, fue el antiguo campesino-minero el que configuró estas imágenes físicas del ente mítico, permitiendo sustentar con fuerza la sensibilidad ante lo diabólico vigente en la mina. ${ }^{27}$

${ }^{25}$ Dice Van Dijk (1989:153-158): "Existen, además, en las narraciones cotidianas, otras categorías, por cuanto la mayoría de los narradores no solo reproducen los sucesos, sino que también aportan su reacción mental, su opinión o valoración. Esta categoría se denomina generalmente Evaluación. Junto a la Trama, la Evaluación forma la verdadera Historia, empleada aquí como término técnico".

${ }^{26}$ Cabe destacar el cercano paralelismo de las imágenes del Diablo percibidas en los relatos del corpus analizado, con las descripciones de este referente mítico que aparecen en el libro Del diablo y otros personajes. (Crónica folklórica de la cuenca del Itata) de Caupolicán Montaldo (1960). Este investigador de los relatos míticos del valle del Itata concentra, en el primer capítulo, trece narraciones donde prevalecen las siguientes descripciones: "hombre vestido de negro", "hombre con dientes de oro", "perro negro", "guagua con dientes de oro", etcétera.

27 Corvalán (1990:19) complementa esta hipótesis, cuando afirma: "Los primeros mineros, campesinos que a mediados del siglo pasado trocaron la luminosidad de los campos por la oscura miseria del fondo de la mina, iniciaron sus nuevas labores 'con lo puesto' (míseras ojotas, raídos pantalones y camisas y chupallas)". Gutiérrez, Mario (2000:493) agrega al respecto: "Pero no sólo el campesino o el indígena se 'enganchaba', sino que también acudían voluntariamente desde distintos puntos de la zona para trabajar en la mina. Muchos llegaban con sus palas, picos y azadones, en carretones y montados a caballo... Esto ocurría por allá por 1853 cuando recién se estaban asentando familias para constituir la villa". 
Un caso mítico representativo que se actualiza mediante la memoria sensorial icónica, asociada al Diablo, es relatado por don Luis Lizama Carrasco, 68 años, exminero de Lota. Este suceso le aconteció a don Luis en una "cancha de carbón" externa a la mina, durante la noche, en el tercer turno:

"Yo tengo uno personal... Yo trabajé en una parte que era la cancha de carbón. Y dicen que ehte señor siempre se iba 'onde hay riquezah... Cuando de repente viene un caballero bien elegante. Y me dijo, era más o menos así gente de bien, me dijo:

-¿Por qué camino, caballero, puedo llegar al...?

- Para ir allí, tiene que ir por ehte camino, pero allí va a quedar encerra'o.

Y lo vi yo con los zapatos brillantitos, su ternito negro bien... eran como las cinco de la mañana. Cuando en esto, le digo:

-Mire, noh vamos a ir por este la'o, yo lo voy a llevar pa' que salga. Le va a salir un poquito más largo, pero...

E: ¿Lo acompañó?

I: Sí. No sé si alguien lo cree o no lo cree, pero cuando nosotros pasábamos, las luceh se apagaban.

E: ¿Las luces eléctricas?

I: ¡Claro! Cuando despuéh llegamos a la vuelta ahí dice:

- iCaballero!, usted ha sido muy amable.

Y me da la mano. Yo lo miro y sonrió. También le vi loh dienteh de oro y sonrió. Y cuando se jue, me acuerdo de la otra historia, y es como que uno acompañó al demonio. Despuéh le conté yo a mi papá, y mi papá me dijo que hice bien de acompañarlo".

En este relato el minero mediante la memoria sensorial icónica describe una imagen del Diablo en que predominan los elementos codificados culturalmente y asimilados al diario vivir dentro y fuera de la mina ("zapatos brillantes", "terno negro" y "dientes de oro"). Además, Lizama evidencia el respeto por los que transitan a diario en este espacio laboral, que incluye tanto lo conocido como lo misterioso. $^{28}$

\section{PROCESOS DE RECUPERACIÓN DE DISCURSOS: RECUERDO Y RECONOCIMIENTO}

De acuerdo con Van Dijk (1980: 88-89): "Hay por lo menos dos clases de recuperación que intervienen en el procesamiento del discurso: la del recuerdo y la del reconocimiento". Relacionando semiótica y psicología cognitiva es

\footnotetext{
28 Al respecto, Eliade (1998:27) manifiesta: "Lo que caracteriza a las sociedades tradicionales es la oposición que tácitamente establecen entre su territorio habitado y el espacio desconocido e indeterminado que les circunda: el primero es el "mundo" (con mayor precisión: "nuestro mundo"), el cosmos; el resto ya no es un cosmos, sino una especie de "otro mundo", un espacio extraño caótico, poblado de larvas, de demonios, de "extranjeros" (asimilados por los demás, a demonios o a fantasmas)".
} 


\section{Juan Bahamonde Cantin}

posible considerar estos procesos como formas de actualización de manifestaciones verbales de carácter mítico.

\subsection{ACTUALIZACIÓN DE LOS DISCURSOS MEDIANTE EL RECUERDO SERIAL}

Para Puente (1998:348), "el recuerdo puede ser de dos clases: libre o serial". En el recuerdo libre "los participantes evocan los eventos, o elementos en el orden que quieren"; en cambio, en el serial, el recuerdo tiene que hacerse según el orden de presentación de los elementos.

Podemos ilustrar el recuerdo serial mediante el extracto de un caso no testimonial, con secuencia lógica, actualizado por el exminero lotino Víctor Gómez Hernández, que el informante titula: Historia del mayordomo que se fue a despedir a la mina:

"El mayordomo de apellido Jerez bajó un día domingo a Pique Grande. El planchero lo bajó en la jaula, llegó abajo e hizo su recorrido. Iba por el tráfico principal de Pique Grande, cuando ya, haciendo el recorrido él se sentó en una banca tranquilamente, miró hacia abajo y vio una luz que venía. Todas las luceh del tráfico estaban encendi(d)as. (En)tonceh dijo:

-Vaya, que raro. Si yo bajé, ¿quién otro máh iba a bajar, si yo estoy de guardia?

Se jue aproximando la luz, y cada vez que venía avanzando el personaje, se iba apagando un foco.

E: ¿Un foco del túnel?

(En)tonceh dijo:

- ¡Pucha!, este es el mayordomo Juan Jiménez. Y cuando llegó frente a él, le dijo:

${ }_{-i \text { Hola! }}$

Y el hombre le dio el saludo y siguió, no sostuvo ninguna conversación con él. Jerez sintió un enfriamiento, como que se le erizaron to(d)os los pelos de la piel. Jue a la boca pique, tocó la campanilla para que lo izaran en la jaula. Sube y le dice al "planchero": 29

-Oye -le dijo- ¿Quién bajó antes de mí?

-Nadie -le dijo.

- ¿Y no viste a Juan Jiménez bajar, al mayordomo?

-No, al contrario. Sabe que llamaron de su casa, de que lo están velando

E: ¿Había fallecido recién?

I: Había fallecido. Este fue un hecho real, contado por el hijo del mayordomo Jerez".

Aunque el relato de don Víctor Gómez no es testimonial, como exminero, conocedor del contexto donde ocurre el suceso misterioso (interior de la mina Pique Grande) y de los protagonistas (el misterioso mayordomo visitante, Juan Jiménez, y el mayordomo de turno, Jerez), se esfuerza por entregar una macroestructura ordenada,

\footnotetext{
${ }^{29}$ Planchero: Se denomina también con este nombre al operador de la jaula, o ascensor de la mina. 
siguiendo la secuencia espacial ("cada vez que avanzaba el personaje, se apagaba un foco") y la ordenación temporal ("esto sucedió un día domingo, en la mañana").

$\mathrm{Si}$ atendemos al contenido del relato, todo minero se siente estrechamente ligado a este submundo, por cuanto ha pasado gran parte de su vida allí, entregando su esfuerzo y su energía. Por eso, antes de alejarse del mundo terrenal acude a despedirse de este espacio subterráneo, al que siente como suyo, para emprender el viaje espiritual definitivo, ${ }^{30}$ ratificando el proceso de empatía del minero con la mina. ${ }^{31}$

Respecto de los relatos míticos (en este caso de contenido "animista") es importante considerar que no hay minero que no haya sido testigo o sobreviviente de un accidente, individual o colectivo, en el interior de las galerías subterráneas. Estos hechos trágicos han originado numerosos relatos vigentes entre los mineros de la cuenca carbonífera.

Por otra parte, mediante el recuerdo serial se han perpetuado en el mundo cultural de Lota y Coronel una serie de leyendas, gracias a que la vida de la familia minera estaba circunscrita a ciertas actividades que permitían la interacción social, como los "lavaderos comunes" y "los hornos colectivos". ${ }^{2}$ Estos espacios se encuentran al servicio de la labor doméstica compartida, donde la mujer del exminero juega un rol preponderante para el intercambio de relatos, posibilitando la preservación de numerosas y representativas leyendas locales. Sobresalen en Lota y Coronel La tacos altos (ver Anexo), Las camas calientes, La guerra del ají, etc. (recordadas por los exmineros de Lota y sus familiares). ${ }^{33}$

\footnotetext{
${ }^{30}$ Eliade (1997:61), al referirse a "la multilocalización paradójica del alma de los muertos", dice: "La convicción casi universal de que los muertos están simultáneamente en la tierra y en el mundo espiritual es muy significativa. Revela la esperanza secreta de que, a pesar de todos los testimonios que aparecen oponerse a ello, los muertos son capaces de participar de alguna manera en el mundo de los vivos".

${ }^{31}$ En Taussig (1993:191) se rescata una afirmación sobre los mineros bolivianos de las minas de estaño: "A los mineros les preocupa la vida de la mina como si fuera una entidad viva... El trabajo del minero es un proceso de empatía con la mina, que la alimenta al mismo tiempo que la excava...".

${ }^{32}$ Corvalán (1990:19) manifiesta al respecto: "Son elementos de tremenda fuerza identificadora; ya que al margen de su función indispensable para la cocción del pan y el aseo de la ropa, respectivamente, asumen la función de centro de vida social, como ya se dijera, en el que existen códigos que deben seguirse en forma rigurosa....".

${ }^{33}$ Las dos últimas leyendas están circunscritas a Lota y fueron narradas sucintamente por don Luis Lizama Carrasco, exminero lotino, mediante entrevista efectuada el 2008. El relato Las camas calientes "tiene relación con la época de prosperidad de la zona minera, especialmente Lota (año 1930 adelante); como faltaba hospedaje para los trabajadores solteros, las familias que ofrecían alojamientos construyeron literas o camarotes para que durmieran dos personas; así, mientras un minero terminaba su turno y se acostaba, el otro se levantaba; de tal manera que la cama no se enfriaba nunca". Por su parte, La guerra del ají versa sobre "una competencia entablada entre los mineros de Lota y Coronel, quienes determinaron encontrarse, yendo por diferentes galerías hacia una misma veta de carbón, hasta que los mineros de Lota provocaron una gran sorpresa, por cuanto el humo picante hizo arrancar a los opositores".
} 


\section{Juan Bahamonde Cantin}

\subsection{ACTUALIZACIÓN DE DISCURSOS MEDIANTE EL RECONOCIMIENTO}

Cabe mencionar que el reconocimiento es el proceso de identificación de algo o alguien como familiar (reconocer nombres, caras, etc.). ${ }^{34}$ Este reconocimiento actúa porque existe algo en la experiencia y en la memoria del sujeto que posibilita el proceso de recuperación y, en consecuencia, es menor el esfuerzo de actualización de la información por parte del informante.

De acuerdo con esto, nuestro corpus presenta numerosos casos míticos testimoniales actualizados por este proceso mnemotécnico. En el relato de don Lorenzo Medina Toloza, exminero de Curanilahue, la relación de algo anteriormente experimentado se conecta de alguna manera con la experiencia presente, contacto que da pie a la sensación de reconocimiento:

"I: Claro. Así que ya, terminamoh de llenar el carbón nosotros; pero sentimoh y fueron como tres paladah que cayeron al carro.

- ¡Ya! -me dijo Pedro- no sentí más palear. Nos quedaba un carro al frente $\mathrm{pa}(\mathrm{ra})$ llenar y todavía son las cuatro de la mañana, podemos alcanzar a echar abajo los arconeh.

-Vamos a echar una mirada.

Pasamos por el frente, por la barra, llegamoh abajo: ahí estaba el montón de carbón, no se había movido un carbón.

E: Pero se escuchó clarito

I: ¿Clarito, claro así! Se suponía que fue "Patas de hilo" el que estaba trabajando".

Este caso mítico se inscribe en la categoría de "fenómenos físicos que proceden de fuente natural", ${ }^{35}$ por cuanto la acción natural ocurrida en el interior de la mina ("sentimos tres paladas que cayeron en el carro"), mediante el proceso de inferencia presenta un sentido que trasciende, en la cosmovisión del minero, más allá de los fenómenos físicos. El informante es portador de un saber sobre esos hechos: "Se suponía que fue 'Patas de hilo' el que estaba trabajando". En otras palabras, en la subcultura minera, el Diablo, dueño simbólico de este espacio obscuro y tenebroso, recobra esta dimensión humana y efectúa las labores rutinarias del quehacer minero.

\footnotetext{
${ }^{34}$ Según Puente (1998:348): "Recuerdo y reconocimiento son procesos diferentes. En el reconocimiento debe haber en la memoria algún tipo de representación permanente de ese algo anteriormente experimentado que se conecta de alguna forma con la experiencia presente y este contacto da pie a la sensación de reconocimiento".

${ }^{35}$ Eco (1995:35), en el capítulo "Límites naturales: inferencia y significación, relacionado con los signos 'naturales', distingue dos tipos de signos: 1) fenómenos físicos que proceden de fuente natural y 2) comportamientos humanos emitidos inconscientemente por los emisores". 


\section{PROCESO DE SEMIOSIS EN LOS DISCURSOS MÍTICOS}

El proceso de semiosis de los discursos míticos lo efectuaremos siguiendo de cerca el modelo de Morris (1985), quien sigue la línea de investigación trazada por Peirce. ${ }^{36}$ Para este último, el concepto de interpretante se puede definir como un signo por medio del cual otro signo se relaciona con su objeto. No obstante, Morris (1985:31-32) distingue tres dimensiones y niveles de semiosis, lo que se traduce en la siguiente división para la semiótica:

a) En la dimensión semántica de la semiosis se estudian las relaciones de los signos con los objetos a los que son aplicables, por lo tanto, se destaca el significado. Ejemplo, en el contexto de la mitología chilota, el canto del "chucao" (ave agorera) puede presagiar buena o mala suerte al caminante.

b) Dimensión pragmática: el objeto de estudio también puede ser la relación de los signos con los intérpretes, en consecuencia, se pone de relieve la acción del intérprete. Ejemplo: la creencia popular chilota dice: "si una persona se olvida de algo y vuelve a buscarlo es señal de que le irá mal; para evitar la acción maléfica debe tomar tres sorbos de agua".

c) Dimensión sintáctica de la semiosis: resalta el orden y organización, en el entendido de que todo signo está relacionado con otros signos. Ejemplo (nuevamente en el contexto chilote): el Intérprete (caminante) reconoce que el canto es del chucao y no de otro pájaro de la montaña; pero, además, distingue si el canto del ave proviene del lado izquierdo (anuncia mal augurio) o derecho (anuncia buen augurio).

Ahora bien, siguiendo la línea del análisis, para Morris (1985:27-28) el proceso en que algo funciona como signo puede denominarse semiosis. Este proceso desde la perspectiva del usuario-informante implica tres factores: lo que actúa como signo (vehículo sígnico), ${ }^{37}$ aquello a que el signo alude (designatum), ${ }^{38}$ y el efecto (o interpretante) que se produce en determinado intérprete en virtud del cual la cosa en cuestión es un signo para él. ${ }^{39}$ En otras palabras, las significaciones y todo el problema del sentido y sus codificaciones y decodificaciones. ${ }^{40}$

5.1. Presentamos mediante un esquema (Tabla 1) el proceso de semiosis (vehículo sígnico, denotatum e interpretante) aplicado a tres casos míticos vigentes en la zona del

\footnotetext{
${ }^{36}$ Charles Morris sigue la línea de investigación trazada por Peirce. La relación triádica que se establece entre el signo, el objeto y el interpretante es definida por Peirce (1988) en los siguientes términos: "un signo, o representamen, es un primero que está en una tal genuina relación triádica a un segundo, llamado su objeto, que es capaz de determinar que un tercero, llamado su interpretante, asuma la misma relación triádica a su objeto en la que él se encuentra respecto del mismo objeto". Cita extraída del artículo de Lada Ferreras (2001:62).

${ }^{37}$ Equivale al "significante", para Saussure; "un signo, o representamen" para Peirce.

${ }^{38}$ Equivale al "significado", para Saussure; "objeto" para Peirce.

39 "Interpretante" para Peirce y Morris, es decir, efecto de sentido.

${ }^{40}$ Pero, además, Morris agrega: "Cuando aquello a que se alude existe realmente como algo referido al objeto de referencia, hablamos de denotatum. De ello se sigue que, si bien todo signo tiene un designatum, no todo signo tiene un denotatum" (1971:30).
} 


\section{Juan Bahamonde Cantin}

carbón relacionados con el Diablo. El primero de ellos corresponde a un caso testimonial y es relatado por don Rosendo Cartes Catril, exminero de Lota. El segundo caso es narrado mediante el recuerdo por don Víctor Gómez, exminero lotino y el protagonista es don Pedro Toledo. Finalmente, el tercer texto es actualizado mediante $\mathrm{el}$ reconocimiento por don Juan Medina, exminero de Curanilahue.

TABLA 1. EL PROCESO DE SEMIOSIS APLICADO A TRES CASOS MÍTICOS VIGENTES EN LA ZONA DEL CARBÓN

\begin{tabular}{|c|c|c|}
\hline $\begin{array}{c}\text { Vehículo sígnico: } \\
\text { lo que actúa como signo }\end{array}$ & $\begin{array}{c}\text { Denotatum: } \\
\text { aquello a que se alude existe } \\
\text { realmente como algo } \\
\text { referido al objeto de } \\
\text { referencia }\end{array}$ & $\begin{array}{c}\text { Interpretante: } \\
\text { el efecto que se produce en determinado } \\
\text { intérprete en virtud del cual la cosa en } \\
\text { cuestión es un signo para él }\end{array}$ \\
\hline $\begin{array}{c}\text { 1. Rosendo Cartes Catril ve, } \\
\text { junto a sus compañeros, una } \\
\text { luz que corre por la viga. }\end{array}$ & $\begin{array}{c}\text { Pensaron que esa luz no era } \\
\text { buena. }\end{array}$ & $\begin{array}{c}\text { Los mineros asociaron esa luz a la presencia } \\
\text { del Diablo. }\end{array}$ \\
\hline $\begin{array}{c}\text { 2. El minero, don Pedro } \\
\text { arrastrado ocho metros, desde } \\
\text { el lugar donde se encontraba } \\
\text { durmiendo ("Corriente } \\
\text { Patagonia"). }\end{array}$ & $\begin{array}{c}\text { Acción atribuida a una } \\
\text { fuerza espiritual que } \\
\text { profundidad de la mina y en } \\
\text { contra de los que laboran y } \\
\text { transitan por esos oscuros } \\
\text { espacios. }\end{array}$ & $\begin{array}{c}\text { El Diablo en los momentos de soledad se } \\
\text { adueña del espacio subterráneo y expresa su } \\
\text { molestia al ver invadido su territorio. }\end{array}$ \\
\hline $\begin{array}{c}\text { 3. Don Juan Medina y su apir } \\
\text { sienten que se abre la puerta } \\
\text { de la "revuelta' (donde salía } \\
\text { el gas viciado)". Ellos } \\
\text { pensaron que era el jefe. }\end{array}$ & $\begin{array}{c}\text { Presencia de un ser maléfico } \\
\text { que anuncia fin del } \\
\text { "laboreo". }\end{array}$ & \\
\hline
\end{tabular}

Siguiendo la lectura de la Tabla 1, podemos evidenciar que los tres casos míticos construyen su macroestructura desde la perspectiva del minero-informante siguiendo el proceso de semiosis. Además, la lectura de los esquemas hace posible determinar la variedad y riqueza de codificaciones (significante, representamen o vehículo sígnico) ${ }^{43}$ existentes en la cultura minera ("luz que corre por encima de una viga", "sonidos de la puerta de 'la revuelta' que se abre", "un minero es arrastrado ocho metros", etc.). Para los informantes (Catril, Toledo y Medina) estas acciones son adjudicadas al Diablo, quien es el "interpretante" en este proceso semiótico.

\footnotetext{
${ }^{41}$ En una entrevista efectuada directamente a don Pedro Toledo, en Coronel (15 de diciembre de 2009), este manifestó que efectivamente fue arrastrado por el Diablo, mientras desarrollaba solo su turno durante la noche en un sector de la mina conocido como "Corriente Patagonia". Este enfrentamiento implicó, además, acciones rituales, exteriorizadas por el minero por manifestaciones verbales (insultos, garabatos, para alejar al Diablo, que lo arrastraba por la galería) y no verbales (gestos de valentía, ánimo y coraje).

${ }_{42}$ Laboreo (Lizama Carrasco, 2010:23): "Sector de explotación del carbón (frente)".

${ }^{43}$ De acuerdo con el concepto propuesto por Saussure, Peirce y Morris.
} 
Así, en el primer relato, para Catril y sus compañeros el personaje mítico genera una nueva cadena de sentidos, donde sucesos posteriores ("Cinco días después paró el trabajo en ese frente y a don Rosendo lo trasladaron a otro lugar de la mina") van ratificando la existencia del Diablo, como ente mítico que influye en el ritmo del trabajo y en el funcionamiento de la mina.

Por su parte, en el segundo relato vinculado a las acciones de don Pedro Toledo acontece la siguiente situación: en el último turno, "el Malulo" se molesta y arrastra físicamente al minero desde el lugar donde se encontraba sentado, para demostrarle su poderío y exigirle autoridad y respeto. Ante estas acciones rituales, el minero Toledo se siente atrapado en la oscuridad e intenta defenderse de la fuerza mítica mediante manifestaciones verbales (insultos, garabatos) y no verbales (gestos de valentía y coraje), ${ }^{44}$ es decir — siguiendo de cerca a Morris - se evidencia la dimensión pragmática del signo.

Finalmente, en el tercer relato, ocurrido a Medina y sus acompañantes, la presencia mítica siempre está presente; por lo tanto el Diablo puede participar en el proceso de producción de la mina e interrumpir la labor en el interior de los socavones en cualquier momento ("Anuncia fin del laboreo");

En definitiva, en los tres casos relatados, el interpretante genera una fuerza maléfica vinculada a un ser que impera dentro del submundo terrestre (la mina carbonífera), asociada al Diablo. En otras palabras, el interpretante de estos textos mineros se va alimentando de muchos signos y construye o cimenta este tipo de semiosis asociada a este espacio, que solo es entendida por los que laboran en estos confines terrestres.

Desde una perspectiva comprensiva, la verdadera lectura del proceso semiótico de estos textos solo es entendida por intérpretes vinculados a esta cosmovisión, pertenecientes a los centros mineros (Coronel, Lota y Curanilahue). ${ }^{45}$ En otros términos, los discursos míticos en estudio solo pueden ser decodificados y comprendidos plenamente por mineros o exmineros de los centros de explotación carbonífera, quienes, con el apoyo de la "otra lógica" (emotiva, concreta, simbólica, etc.) del pensamiento mítico (Carrasco, 1989), pueden relacionar adecuadamente el proceso de semiosis de los discursos en todos sus planos. Por lo tanto, el Diablo, como interpretante, genera sentidos que van a justificar posteriormente acciones, eventos, conductas que retroalimentan la atmósfera maléfica que impera en la mina.

\footnotetext{
44 Acción contrarrestada por el minero mediante rituales paganos, que se expresan por manifestaciones verbales y no verbales. Por lo tanto, en este espacio laboral lo "pagano" se opone a lo "religioso", porque todos los mineros encuestados coincidieron en manifestar que dentro de la mina era tabú mencionar palabras o expresiones relacionadas con la doctrina cristiana. Don Carlos Retamal Rosales, exminero lotino, católico practicante, en reiteradas conversaciones sobre el trabajo minero manifestó: "Antes de ingresar a la mina siempre me persignaba, pero adentro solo rezaba mentalmente, porque no sabía si iba a regresar o no".

${ }^{45}$ El otro yacimiento carbonífero importante de la Región del Biobío estuvo ubicado en Lebu. Relatos aportados por mineros lebulenses serán considerados en artículos posteriores.
} 


\section{Juan Bahamonde Cantin}

En suma, cuanto más situaciones maléficas acontecen dentro de la mina, más se acrecienta el proceso de semiosis atribuido a la presencia y construcción de este ente mítico.

5.2. Presentamos mediante un esquema (Tabla 2) el proceso de semiosis (vehículo sígnico, denotatum e interpretante) aplicado a la leyenda La tacos altos, vigente en Coronel, apoyándonos en la versión entregada por don José Bascur Ramírez (19 de mayo de 2009), exminero de Schwager y residente en el edificio ubicado en Puchoco.

TABLA 2. EL PROCESO DE SEMIOSIS APLICADO A UNA LEYENDA DE LA ZONA DEL CARBÓN

\begin{tabular}{|l|l|l|}
\hline $\begin{array}{l}\text { Vehículo sígnico: lo que actúa } \\
\text { como signo. }\end{array}$ & $\begin{array}{l}\text { Denotatum: aquello a que se alude } \\
\text { existe realmente como algo } \\
\text { referido al objeto de referencia. }\end{array}$ & $\begin{array}{l}\text { Interpretante: el efecto que se } \\
\text { produce en determinado intérprete } \\
\text { en virtud del cual la cosa en } \\
\text { cuestión es un signo para él. }\end{array}$ \\
\hline $\begin{array}{l}\text { Don José Bascur dice: "Se escucha } \\
\text { el caminar de la mujer en los } \\
\text { pasillos y se ve la figura atravesar } \\
\text { los muros del departamento donde } \\
\text { vivía". }\end{array}$ & $\begin{array}{l}\text { Presencia de un espíritu maléfico } \\
\text { ("mujer fatal") en el edificio de }\end{array}$ & $\begin{array}{l}\text { La "Tacos altos": espíritu de la } \\
\text { leyenda. }\end{array}$ \\
\hline
\end{tabular}

La lectura del esquema permite determinar que en el proceso de semiosis de la leyenda el interpretante proviene de una lógica previa construida colectivamente mediante la oralidad, cuyo signo se refuerza por la memoria ecoica ("se escucha el caminar de la mujer") e icónica ("se ve la figura atravesar los muros del departamento donde vivía"). Además, el vehículo sígnico que refuerza al proceso de semiosis de la leyenda está delimitado por la misma historia (macroestructura), ejemplo: cada vez que se escucha el caminar o el taconeo, los habitantes del edificio del sector Puchoco lo asocian a "La tacos altos" (o la "mujer fatal"). En cambio, el vehículo sígnico que refuerza el proceso de semiosis de los tres casos míticos en estudio, como se pudo determinar más arriba, está delimitado por el contexto de la mina (en la soledad de las galerías se ven luces, se sienten ruidos, impera una fuerza física, etc.).

\section{DIFERENCIAS ENTRE EL CASO Y LA LEYENDA, A NIVEL SEMIÓTICO}

Aunque los procesos de análisis se han centrado preferentemente en el caso, es posible establecer algunas diferencias a nivel de rasgos discursivos estructurales entre estas dos superestructuras utilizadas por los mineros-informantes de la zona del carbón: el caso y la leyenda. ${ }^{46}$ Estas distinciones se efectuarán a nivel de cinco rasgos estructurales seleccionados, que predominan en estas manifestaciones orales. La leyenda, como superestructura, se complementará con las dos versiones de $\mathrm{La}$

\footnotetext{
${ }^{46}$ Bahamonde en su Tesis Doctoral (2008:187-192) establece diferencias entre caso y leyenda, considerando seis elementos estructurales: a) influencia de la comunidad en el usuario-informante; b) temporalidad del suceso; c) tipo de memoria sensorial que predomina; d) forma de actualización como discurso; e) reacción del usuario-informante ante el evento y, por último, f) proceso de semiosis.
} 
tacos altos, recopiladas en Coronel (como se manifestó más arriba, una narración fue entregada por don José Bascur Ramírez y la otra más completa, transcrita en el Anexo, por don Mario Gutiérrez Córdova).

a) El usuario-informante y su vinculación con el suceso que narra

Este rasgo es importante en la leyenda, por cuanto cada miembro activo de la comunidad es conocedor general o parcial de esta historia con huellas de verdad. El minero-informante o algún integrante de su familia relata mediante el recuerdo una versión que se constituye como variante del relato conocido en la comunidad minera. Por lo tanto, se trata de un discurso socializado. Ejemplo: "Dicen los schwagerinos habitantes de los colectivos que todavía se ve la figura de la mujer, y se escucha el caminar de esta en los pasillos..." (ver Anexo).

En la narración del caso, el minero-informante relata una versión, general o parcial, de un suceso conocido por él (centrado en un evento en donde predomina el contenido mítico), actualizado como testimonio o recuerdo.

b) Tipo de memoria sensorial que predomina, como procedimiento de rememoración

Como procedimiento de rememoración, en el caso predomina la memoria ecoica (lo escuchado) e icónica (lo visto).

Por su parte, siguiendo el proceso de rememoración, en la leyenda prevalece la memoria ecoica (lo escuchado) y la memoria serial, por ser un relato ordenado, que sigue una secuencia lógica y coherente. Para don José Bascur Ramírez, por ejemplo, todos los habitantes de los colectivos de Puchoco conocen el relato de La tacos altos.

c) Forma de actualización como discurso (procesamiento cognitivo)

El caso se transmite por medio de la vía oral y la forma de actualización como acto verbal del hecho acontecido por el minero-informante es mediante un acto de enunciación. ${ }^{47}$ Es decir, el relato está centrado en un evento testimonial de contenido mítico, generado en el extratexto, que el informante haciéndose cargo de la situación lo relata en primera persona, actualizándolo por el reconocimiento (ver este concepto en el punto 4.2). Pero también el relato se vincula a un evento de contenido mítico, generado en el extratexto, que le aconteció a un antepasado o familiar del informante; por lo tanto, el narrador no se hace cargo de la situación y lo relata en tercera persona, es decir, se actualiza mediante el recuerdo.

No obstante, el relato está centrado en una historia lejana, con personajes del mundo real y mítico y de trascendencia en la comunidad. El narrador-informante, incluyendo a su familia, ha escuchado esta narración de sus antepasados y la actualiza, en tercera persona, por medio del recuerdo. Ejemplo: "Y de vez en cuando

\footnotetext{
${ }^{47}$ Benveniste (1977:83-85) define este concepto de la siguiente manera: "La enunciación es este poner a funcionar la lengua por un acto individual de utilización”. Más adelante agrega el lingüista: “...el término yo denota al individuo que profiere la enunciación, el término tú, al individuo que está presente como alocutorio".
} 


\section{Juan Bahamonde Cantin}

se ve la figura de la mujer atravesar los muros del departamento donde ella vivía". En otras palabras, en la leyenda, normalmente, no existe el reconocimiento (el narrador no se hace cargo de la situación), ya que el evento primordial ocurrió hace muchísimos años, en un tiempo fuera del tiempo.

d) Reacción del usuario-informante de acuerdo con el evento, en el momento de la narración

Siguiendo a Van Dijk, ${ }^{48}$ en el caso al finalizar la narración prácticamente todos los informantes relatan la reacción consciente que experimentan ante ese evento, conocido en el ámbito de las estructuras narrativas como "Evaluación". Ej.: Tiene que haber sido el Maldito.

En la leyenda, en cambio, al finalizar la narración el usuario-informante no experimenta esta reacción mental consciente para evitar maleficios; por lo tanto, hay ausencia de la categoría "Evaluación".

e) El proceso de semiosis

A nivel de semiosis, proceso que desde la perspectiva del minero-informante implica tres (o cuatro) factores: vehículo sígnico, designatum o denotatum e interpretante (e intérpretes) (Morris, 1971:27-28), la situación es la siguiente:

En la leyenda mítica (ejemplo: La tacos altos, versión de don José Bascur Ramírez) sucede lo siguiente: como la macroestructura circula por la oralidad entre los habitantes del edificio de Puchoco (de una generación a otra), el interpretante, caracterizada como "La tacos altos" (o "la mujer fatal" que transita por el edificio), participa en una semiosis localizada, que se alimenta del conocimiento previo de una historia específica, asociada a las ánimas que penan.

En el caso, como sucede en este proceso de análisis centrado en el Diablo, el proceso de semiosis no requiere del conocimiento de una historia puntual rememorada en la comunidad, sino que se desgaja de un ente omnipresente que se ha construido como interpretante, junto a los numerosos sucesos que acontecen en la mina.

\footnotetext{
${ }^{48}$ A manera de complementación, este comportamiento se asemeja a la Evaluación (Van Dijk 1989:155), categoría que de acuerdo con este estudioso de las "estructuras narrativas" no pertenece a la TRAMA, y tiene relación con la reacción mental que experimenta el narrador ante los sucesos.
} 


\section{CONCLUSIONES}

Finalmente, el desarrollo de este trabajo nos ha permitido determinar que en este escenario, conformado por un verdadero laberinto de galerías submarinas, situado en la Región del Biobío, predominan en la memoria de los exmineros dos tipos de relatos misteriosos, asociados a las creencias: los casos míticos y los casos animistas. Además, en cada ciudad de la cuenca carbonífera se han perpetuado representativas leyendas, gracias a que la vida de la familia minera estaba circunscrita a ciertas actividades que permitían la interacción social.

De igual forma, podemos evidenciar que el pensamiento mítico es uno de los componentes de la memoria cultural de este grupo humano (exmineros de cuenca del carbón), que se define por la capacidad de reactualizar oralmente un cierto evento primordial, registrado genéricamente como caso mítico. En todos estos relatos, el Diablo aparece como el protagonista principal, cuya fuerza demoníaca ha influido en forma notoria, tanto en el ritmo laboral de los mineros como en el destino de este espacio.

Desde el punto de vista de la memoria sensorial (ecoica e icónica), en los textos en estudio (casos y leyendas), podemos comprobar que esta no solo contribuye a determinar el proceso de actualización del discurso, sino también a analizar la descripción de la representación sensorial que se evidencia en el texto y su relación con el sentido que el propio minero-informante da al elemento mítico o animista.

De igual manera, el recuerdo serial nos ha permitido comprender y destacar cómo los informantes, al utilizar este tipo de memoria, son capaces de ordenar secuencialmente el relato y de situarlo dentro de las coordenadas de tiempo y espacio.

Si bien es cierto que solo se analizan tres casos míticos siguiendo el proceso propuesto por Morris; no obstante se puede determinar que cuanto más situaciones maléficas acontecen en este espacio minero, más se acrecienta el proceso de semiosis atribuido a la presencia de este ente mítico (interpretante), que impera con fuerza en el interior de la mina.

En definitiva, ambas disciplinas básicamente consideradas, la semiótica y la psicología cognitiva, han permitido confirmar que estamos ante dos importantes procesos de actualización de los discursos orales: el recuerdo y el reconocimiento. Además, la aplicación de estas disciplinas a los textos en estudio (caso y leyenda) contribuyen en la determinación de rasgos discursivos y genéricos específicos, señalados en los análisis respectivos.

Universidad del Bío-Bío* Departamento de Estudios Generales Avda. Collao 1202, Concepción (Chile) jbahamon@ubiobio.cl 


\section{OBRAS CITADAS}

Bahamonde Cantín, Juan. Creencias, casos y leyendas en la cultura contemporánea de Chiloé: análisis semiótico y cognitivo. Tesis Doctoral.

Valdivia: Universidad Austral de Chile. Inédita, 2008.

Benveniste, Émile. Problemas de Lingüistica General II. México: Siglo XXI Editores, S. A., 1977.

Carrasco, Hugo. El sistema funcional de los mitos mapuches. Tesis Doctoral. Santiago: Universidad de Chile. Inédita, 1989.

Cassirer, Ernst. Mito y Lenguaje. Buenos Aires: Ediciones Galatea/Nueva Visión, 1959.

Cassirer, Ernst. Antropología Filosófica. México: F.C.E., 1971.

De Vega, Manuel. Introducción a la psicología cognitiva. Madrid: Alianza Editorial, 1998.

Eco, Umberto. Tratado de semiótica general. Barcelona: Editorial Lumen, 1995.

Eliade, Mircea. Lo sagrado y lo profano. Barcelona: Paidós Orientalia, 1998.

Eliade, Mircea. Ocultismo, brujería y modas culturales. Barcelona: Paidós, 1997.

Lada Ferreras, Ulpiano. "La dimensión pragmática del signo lingüístico", en Estudios Filológicos 36. Valdivia: Universidad Austral de Chile, 2001:61-70.

Malinowski, Bronislaw. "El mito en la psicología primitiva", en Estudio de la psicología primitiva. Buenos Aires: Editorial Paidós, $3^{\text {a }}$ edición, 1963.

Malinowski, Bronislaw. Magia, ciencia, religión. Barcelona: Editorial Ariel, S.A., 1982.

Morris, Charles. Fundamentos de la teoría de los signos. México: Paidós, 1985.

Ong, Walter J. Oralidad y Escritura. Tecnología de la palabra. México: Fondo de Cultura Económica, tercera reimpresión, 1999.

Peirce, Charles Sanders. El hombre, un signo (El pragmatismo de Peirce). Barcelona: Crítica, 1998.

Pike, Kenneth. Language in Relation to a Unified Theory of the Structure of Human Behavior, Vol 1. Glendale, C A: Summer Institute of Linguistics, 1954.

Puente Ferreras, Aníbal. Cognición y aprendizaje. Fundamentos psicológicos. Madrid: Ediciones Pirámide, S.A., 1998.

Saussure, Ferdinand de. Curso de lingüistica General. Madrid: Alianza Universitaria, 1987.

Taussig, Michael T. El diablo y el fetichismo de la mercancía en Sudamérica. México: Editorial Nueva Imagen, 1993. 
Van Dijk, Teun. Estructuras y funciones del discurso. México: Siglo Veintiuno Editores, 1980.

Van Dijk, Teun. La ciencia del texto. México: Paidós, 1989.

\section{ESTUDIOS SOBRE LA ZONA DEL CARBÓN}

Astorquiza, Octavio. Cien años del carbón de Lota. Santiago: Editora Zig-Zag, S.A., 1952.

Astorquiza, Octavio. Lota: Antecedentes históricos, con una monografía de la Compañia Carbonifera e Industrial de Lota en ocasión de celebrar el $90^{\circ}$ aniversario de la explotación de las minas (1852-1942). Valparaíso: Universo, 1942.

Corvalán, Gregorio. Gente del carbón (Kuyulche). Concepción: Ediciones Letra Nueva, 1990.

Elizalde, Miguel. Pueblo Nuevo. Historia, Mitos y Leyendas de la Zona del Carbón. Inédito, 2006.

Gutiérrez, Mario et al. Coronel de ayer y de hoy. Talcahuano: Talleres de Trama, 2000.

Impresores S. A. Lillo, Baldomero. Obras Completas. Santiago: Editorial Nascimento, 1968.

Lizama Carrasco, Luis. Terminología del vocablo minero. Lota. Inédito, 2010.

Montaldo, Caupolicán. Del diablo y otros personajes (Crónica folklórica de la cuenca del Itata). Chile: Universidad de Concepción, 1960.

Parada, Enrique; Valdivieso, Humberto. El léxico de las minas del carbón. Lota. Concepción: Universidad de Concepción, Publicaciones del Instituto Central de Lenguas, 1974.

Uribe Ulloa, Héctor. Folklore y tradición del minero del carbón. Concepción: Editora Aníbal Pinto S. A., 1998.

\section{ANEXO}

Leyenda: La tacos altos

Versión relatada por don Mario Gutiérrez Córdova, 63 años, profesor jubilado, historiador y recopilador de relatos orales de Coronel. Recogida en la ciudad minera de Coronel el 24 de septiembre de 2008, por Juan Bahamonde y Margarita Gatica. Además, la entrevista fue reiterada el 5 de mayo de 2009. 


\section{Juan Bahamonde Cantin}

\section{Texto}

I: Cuando Schwager estaba en su opulencia, la empresa construyó los actuales colectivos en el sector Puchoco. ¿Qué característica tienen estos colectivos? Sus departamentos son muy grandes, reúnen todas las condiciones porque tienen tres dormitorios, un buen living-comedor, cocina y baño. Pero, la galería que une los diferentes departamentos es demasiado estrecha y nunca después que cerró la mina los habitantes le han colocado luces a estos pasajes, a estos pasadizos, por lo que siempre permanecen a oscuras. Y allí, para mirar hacia fuera, existen balcones que unen diferentes pabellones (...) Pues bien, ¿Qué sucedió? Como decía yo, cuando la mina era próspera, llegó a vivir a uno de los departamentos un matrimonio joven. La señorita, o la señora, era una mujer muy linda, delgadita, que tenía por característica usar taco alto, con muñecas llenas de joyas, de (...) pulseras, que cuando caminaba le sonaban. Quedó embarazada, pero con tal mala suerte que Dios quiso que la guagua se fuera de inmediato, una vez que nació, al cielo.

E: ¿Falleció?

I: Falleció. La mujer se volvió loca y recorría los pasillos de los departamentos desesperada buscando a su hijo. Con el correr del tiempo, ella falleció. Dicen los schwagerinos que todavía se ve la figura de la mujer, y se escucha el caminar de la mujer en los pasillos, y de vez en cuando se ve la figura atravesar los muros del departamento donde ella vivía.

El marido al poco tiempo dejó el departamento y se fue. Pero las mujeres y los hombres de Schwager todavía creen ver y escuchar a la "Tacos altos" caminar por los pasillos. Por este motivo no envían a comprar, o hacer diligencias a sus hijos a Schwager o a Coronel, en el invierno, para que ellos no se encuentren con la "Tacos altos". 